\title{
Padrões de seletividade relacionados aos casais homossexuais e heterossexuais no Brasil
}

\author{
Fernanda Fortes de Lena* \\ Ana Maria Hermeto Camilo de Oliveira*
}

\begin{abstract}
Esse artigo tem por objetivo analisar os padrões de seletividade marital entre os casais heterossexuais e os casais homossexuais no Brasil, investigando os níveis de escolaridade, cor/raça e grupo etário. Inicialmente foi feita uma análise descritiva dos dados com o intuito de caracterizar a população estudada e os diferenciais entre os tipos de casais. Além disso, esse artigo utiliza tabelas de contingência e modelos log-lineares para compreender as formas de associações entre os casais e quais variáveis influenciam a seletividade dos parceiros. Os resultados mostram que cor/raça e escolaridade têm maior influência na seletividade dos casais heterossexuais, enquanto cor/raça e grupo etário são mais relevantes para os casais homossexuais em relação aos seus padrões de seletividade. Portanto, é possível identificar a existência de diferenças entre as características de seletividade entre esses casais e seus padrões, o que abre margem para estudos posteriores que possam aprofundar a compreensão das distinções entre esses padrões, no sentido de encontrar formas de tentar explicá-las e suas possíveis consequências no Brasil.
\end{abstract}

Palavras-chave: Seletividade marital. Homossexuais. Casamento. Educação. Arranjos familiares.

\footnotetext{
*Universidade Estadual de Campinas - Unicamp, Campinas-SP, Brasil (flena@nepo.unicamp.br).

** Universidade Federal de Minas Gerais - UFMG, Belo Horizonte-MG, Brasil (ahermeto@cedeplar.ufmg.br).
} 


\section{Introdução}

Esse artigo se propõe a testar a hipótese de seletividade marital entre casais heterossexuais e homossexuais no Brasil. 0 estudo a respeito das escolhas conjugais na sociedade é importante nos âmbitos econômico e demográfico, pois retrata as preferências dos indivíduos na formação da família, a divisão sexual do trabalho do casal tanto no mercado de trabalho quanto no ambiente domiciliar, além de ser um aspecto fundamental para a transmissão intergeracional das desigualdades socioeconômicas (LIMA, 1999). Nesse artigo, focaliza-se o caráter endogâmico ou exogâmico dos casais de acordo com as características educacionais, raciais e por faixa etária. Um estudo mais detalhado sobre as formações dos casais seria desejável, mas existem limitações quanto às informações disponíveis para essas análises, principalmente no que diz respeito à divisão sexual do trabalho.

Há uma extensa literatura nacional e internacional que trata da seletividade marital entre casais heterossexuais, levando em conta características educacionais, raciais, de renda, entre outras. No entanto, a oportunidade de se estudar a seletividade marital entre casais homossexuais no Brasil surgiu apenas partir do Censo Demográfico de 2010, com a inclusão, no questionário, da opção "cônjuge do mesmo sexo" no quesito de relação de parentesco, tornando possível a análise dos padrões de seletividade dos casais homossexuais brasileiros.

A importância de se estudar essa parcela da população está relacionada ao fato de que tais casais fazem parte da sociedade e, portanto, merecem a devida atenção por serem sujeitos sociais com direitos à constituição de uma família e direitos sexuais e reprodutivos. Luiz Mello (2005, p. 200) faz referência à importância da conjugalidade homossexual como constituição de família:

Por meio da constituição de casais conjugais, cujos membros geralmente se autodefinem como uma família, os homossexuais [...] reivindicam não mais apenas o direito à cidadania, em nível individual, mas, também, o direito à constituição de grupos familiares, integrando-se ao rol de sujeitos sociais portadores de demandas que, no mundo ocidental, convencionalmente realizam-se por meio da constituição do casal conjugal.

Logo, o reconhecimento da existência desses tipos de casais na sociedade contemporânea coloca a necessidade de se investigar o tema para que se tenha um entendimento melhor acerca dos arranjos familiares brasileiros. Assim, esse artigo procura contribuir para uma maior compreensão dos diferentes arranjos familiares no Brasil, oferecendo subsídios para possíveis desdobramentos analíticos em termos da análise dos processos de estratificação social.

\section{Revisão da literatura}

Ao abordar o tema de seletividade marital, deve-se considerar a amplitude de teorias que há décadas tentam explicar porque as pessoas tendem a se casar dentro de um mesmo 
grupo (endogamia) e com status social semelhante (homogamia). Dada a complexidade do assunto, existem várias vertentes do conhecimento que tomaram para si a responsabilidade de tentar entender tal fenômeno e até medi-lo. É nesse sentido que o objeto tratado nesse trabalho espalhou-se entre as áreas da sociologia, ${ }^{1}$ economia, demografia, entre outras.

Entre os economistas, Becker (1981) foi um dos primeiros a desenvolver uma teoria microeconômica que disserta a respeito da seletividade marital de forma quantitativa. Segundo o autor, no mercado matrimonial existe um equilíbrio no qual a pessoa decide casar se, e somente se, a utilidade do casamento for maior que a de permanecer solteiro. Além do fator utilidade, há duas outras variáveis que incidem sobre a decisão de se casar ou não: a função de produção no domicílio e a oferta de potenciais parceiros. A utilidade nesse caso não depende dos bens comprados pelo domicílio, mas sim dos bens produzidos pelo domicílio, como qualidade das refeições, qualidade e quantidade de filhos, prestígio, recreação, companheirismo, amor e saúde. Como é possível perceber, esses bens não são quantificáveis como bens de consumo, mas Becker (1981) assume que se pode colocá-los todos em uma função agregada (Z).

De acordo com Becker (1981), as associações no mercado matrimonial representam a busca de um parceiro que aumenta a utilidade de ambos, independentemente se o fator é financeiro, biológico ou psicológico. No entanto, a composição populacional, assim como outras forças sociais, funciona como um fator importante que afeta a busca pelo parceiro. Dessa forma, se os indivíduos pertencem a grupos mais populosos, maiores são as chances de se encontrarem pessoas com características semelhantes formando uma união endogâmica. Se o indivíduo pertence a uma população menor, suas chances são mais restritas, podendo haver maiores chances de uma união exogâmica. Isso é o que propõe a teoria de Blau e Schwartz (1984), dado que os casamentos ocorrem aleatoriamente, mas existem questões sociais e demográficas que afetam essas escolhas. A literatura relata que as taxas de endogamia e exogamia observadas em qualquer sociedade são produtos de forças sociais relacionadas: preferências e vontades individuais; influências dos grupos ou normas sociais; e características estruturais dos mercados matrimoniais (RIBEIRO; SILVA, 2009).

Os trabalhos de Ribeiro e Silva (2009) e Longo (2011) são os mais recentes que utilizam o Censo Demográfico de 2000 para estudar os padrões de associações dos casais heterossexuais no Brasil. Ribeiro e Silva (2009) escolheram as variáveis cor/raça e escolaridade para identificar as barreiras existentes entre as uniões. Além disso, os autores utilizam dados dos Censos Demográficos de 1960 até 2000 como forma de verificar as diferenças dos padrões em diversos períodos, indicando um aumento nos casamentos inter-raciais no Brasil ao longo do tempo e uma diminuição das barreiras educacionais entre os casais. Além disso, eles destacam ainda que há uma redução das barreiras entre brancos e pardos maior do que entre pardos e pretos. Mais do que isso, essas tendências são independentes dos níveis educacionais das pessoas.

\footnotetext{
${ }^{1}$ Entre os trabalhos de sociólogos, o artigo de Kalmijn e Flap (1998) faz uma revisão dos estudos que tratam de seletividade marital na área da sociologia.
} 
Longo (2011) investigou as formas de associação dos casais a partir das variáveis cor/ raça, escolaridade e religião dos cônjuges, de forma a demonstrar como ocorre a seletividade das mulheres entre 20 e 29 anos no Brasil. Os resultados encontrados pela autora tendem para as mesmas conclusões feitas por Ribeiro e Silva (2009). No entanto, os estudos de Longo (2011) vão mais a fundo nas questões de escolaridade, raça e religião, fazendo uma relação entre as variáveis com modelos log-lineares e topológicos. Os resultados dos modelos revelam que, no caso da escolaridade, um indivíduo de cor/raça de menor status social tem mais chance de se unir a um parceiro de uma cor/raça de maior status social quando as diferenças nos níveis de escolaridade compensarem essas diferenças raciais. Isso demonstra que, embora haja uma diminuição nas barreiras raciais nas uniões, o fator escolar é ainda muito forte, sendo utilizado como compensatório no status social. Em relação à religião, os resultados demonstraram seu forte poder na escolha do parceiro e não pode ser usada como característica de troca entre diferenças raciais. Dessa forma, percebe-se que, no Brasil, as barreiras de religião perpassam as barreiras de escolaridade e raça em se tratando da rigidez, mostrando claramente o peso que essa característica tem na formação das famílias.

No que se refere à literatura internacional sobre casais do mesmo sexo, há evidências que indicam uma diferença na forma de escolha do parceiro quando comparados aos casais de sexos opostos (BADGETT, 2001). Alguns autores explicam que essas diferenças devem-se à especialização de sexo na divisão sexual do trabalho, o que não ocorre com tanta frequência entre casais do mesmo sexo.

Jepsen e Jepsen (2002) utilizaram dados do Censo de 1990 para estudar a seletividade marital entre casais homossexuais e heterossexuais nos Estados Unidos. Os autores abordam a diferença de seletividade entre quatro tipos de casais: casais de homens, casais de mulheres, casais de sexos opostos conviventes e casais de sexos opostos casados. Os resultados desse estudo demonstram uma clara diferença entre as preferências de características para cada tipo de casal. Em relação às variáveis cor/raça e idade, observou-se que os coeficientes de correlação são maiores entre os casais de sexos opostos casados e depois entre os casais de sexos opostos conviventes, sendo os menores níveis de correlação dessas características entre casais de mesmo sexo. No entanto, correlações para escolaridade não mostraram nenhuma distinção entre os tipos de casais. Já para as características de mercado de trabalho, como ganhos por hora, renda e horas trabalhadas, as correlações menores ocorrem para casais de sexos opostos casados, seguidos por casais de sexos opostos conviventes, enquanto as maiores são verificadas para casais de mesmo sexo. Por fim, os autores chegam à conclusão de que os resultados sugerem que os casais de todos os tipos preferem pessoas com características similares às deles, tanto para variáveis pessoais como para aquelas de mercado de trabalho. 0 estudo de Jepsen e Jepsen (2002) demonstra que a composição de gênero do casal influenciará nas preferências ditas de mercado de trabalho. Isso sugere uma distinção na divisão sexual do trabalho entre casais do mesmo sexo, que, segundo os estudos citados, tende a não seguir os padrões heteronormativos. 


\section{Metodologia}

0 primeiro método utilizado nesse estudo corresponde às tabelas de contingência usuais em trabalhos sobre seletividade marital, as quais possibilitam fazer o cruzamento das características entre os responsáveis ${ }^{2}$ pelos domicílios e seus cônjuges, bem como analisar a distribuição dessas associações na tabela. As uniões ocorrem de duas formas: quando indivíduos de características semelhantes se unem, chamada de endogamia ou homogamia; e quando ocorre a união entre indivíduos com características distintas, conhecida como exogamia ou heterogamia. Após a padronização das tabelas por meio do método IPF (Iteractive Proportional Fitting), ${ }^{3}$ são calculadas as taxas de endogamia e exogamia na população, proporcionando uma melhor visualização do caráter endogâmico ou exogâmico dos casais em relação às características analisadas.

Partindo das tabelas de contingência, a metodologia utilizada de modelos log-lineares avança, ao permitir a decomposição dos efeitos de tamanho dos grupos na população do efeito da associação estatística entre características dos cônjuges na escolha marital. Essa separação de efeitos é importante, pois revela as preferências individuais e/ou normas sociais dos grupos que estabelecem os padrões das uniões.

O modelo log-linear capta ambos os efeitos: "principal” e "interação". O modelo que contém todos os efeitos possíveis é chamado de modelo saturado, o qual reproduz perfeitamente a tabela original de frequências observadas. Neste modelo, o número de parâmetros independentes é igual ao número de células da tabela de contingência. 0 modelo saturado é o seguinte:

$F_{i j}=\eta \tau_{i}^{C} \tau_{j}^{O} \tau_{i j}^{C O}$

Onde: $F_{i j}$ é a frequência esperada na célula $i j ; \eta$ refere-se à média geométrica das frequências em cada célula da tabela (este termo assemelha-se ao intercepto da equação de regressão linear); os termos $\tau_{i}^{C} \tau_{j}^{O}$ são efeitos das margens ou distribuições de associações sobre a frequência na célula $i j$; e $\tau_{i j}^{C O}$ corresponde aos efeitos da interação das distribuições de associações sobre a frequência na célula $i j$.

\section{Base de dados}

A base de dados do Censo Demográfico de 2010 utilizada é composta de 64.451 casais $^{4}$ do mesmo sexo e 36.201.272 casais de sexos opostos. É importante ressaltar que o Censo Demográfico de 2010 só permite captar casais residentes no mesmo domicílio. Logo, deve-se ter em mente essa limitação dos dados quanto ao número de casais tanto

\footnotetext{
${ }^{2}$ Segundo o IBGE (2010, p. 30) a pessoa responsável pelo domicílio é: “a pessoa (homem ou mulher), de 10 anos ou mais de idade, reconhecida pelos moradores como responsável pela unidade domiciliar".

${ }^{3}$ Para mais informações sobre o método, ver Agresti (1990).

${ }^{4}$ Foram retirados da amostra os indivíduos que não declararam escolaridade, cor/raça ou idade. Além disso, foram excluídos da amostra indivíduos que se declararam amarelos ou indígenas.
} 
heterossexuais quanto homossexuais no país. Dessa forma, as análises feitas nesse trabalho dizem respeito aos casais corresidentes tanto heterossexuais como homoafetivos.

Decidiu-se manter os indivíduos com idades de 18 a 65 anos ou mais, que posteriormente foram subdivididos em grupos etários quinquenais. A decisão por esse corte etário está relacionada com a perda de observações e também pelo fato de se estar analisando a seletividade em relação ao grupo etário. Portanto, ao se restringir a faixa etária estudada poder-se-ia estar influenciando as taxas de exogamia entre os casais. É claro que essa decisão influi na variável de escolaridade, em função do seu caráter mutável ao longo dos anos. Como não há dados sobre a data da união dos casais, a semelhança ou disparidade de escolaridade pode ter ocorrido posterior à união. Argumenta-se que, devido a essa limitação de informação, optou-se por estudar as escolhas dos casais de estarem unidos em 2010.

A variável de nível de instrução é a mesma existente no banco de dados do Censo de $2010,{ }^{5}$ sendo apenas substituídas as nomenclaturas do IBGE para as categorias pelas seguintes entre parênteses: sem instrução e fundamental incompleto ( 0 a 7 anos); fundamental completo e médio incompleto (8 a 10 anos); médio completo e superior incompleto (11 a 14 anos); e superior completo (15 anos ou mais). A escolha por essa denominação advém de uma melhor noção de quantos anos de estudo têm as pessoas em cada categoria.

\section{Análise descritiva}

A descrição da composição dos grupos estudados revela semelhanças e disparidades entre os casais. Esses diferencias podem indicar possíveis comportamentos quanto à escolha do parceiro. No entanto, somente a partir das taxas de endogamia e exogamia, além dos modelos log-lineares, pode-se analisar de maneira mais completa as uniões estabelecidas entre os casais. A Tabela 1 revela que o nível de instrução dos casais homossexuais tem uma distribuição quase que homogênea entre os níveis escolares, tendo uma concentração maior (39,45\% e 40,55\%) na faixa de 11 a 14 anos de estudo. Já entre os casais heterossexuais há uma maior concentração (49,99\% e 47,97\%) no nível de 0 a 7 anos de estudo. Black, Sanders e Taylor (2007), utilizando o Censo de 2000, obtiveram resultados semelhantes sobre a escolaridade de casais homossexuais nos EUA, que também são mais escolarizados do que os heterossexuais.

\footnotetext{
${ }^{5}$ Essa é uma variável auxiliar, estimada por aproximação pelo IBGE, visto que o Censo Demográfico de 2010 não captou a informação sobre última série concluída com aprovação para pessoas que não frequentavam a escola no momento da pesquisa.
} 
TABELA 1

Distribuição dos casais heterossexuais e homossexuais, segundo nível de instrução, cor/raça e grupo etário

Brasil - 2010

\begin{tabular}{|c|c|c|c|c|}
\hline \multirow{3}{*}{ Variáveis } & & & & Em porcer \\
\hline & \multicolumn{2}{|c|}{ Casais heterossexuais } & \multicolumn{2}{|c|}{ Casais homossexuais } \\
\hline & Responsável & Cônjuge & Responsável & Cônjuge \\
\hline \multicolumn{5}{|l|}{ Nível de Instrução } \\
\hline 0 a 7 anos & 49,99 & 47,97 & 18,04 & 19,36 \\
\hline 8 a 10 anos & 15,76 & 16,44 & 14,17 & 15,6 \\
\hline 11 a 14 anos & 24,12 & 25,49 & 39,45 & 40,55 \\
\hline 15 anos ou mais & 10,14 & 10,11 & 28,33 & 24,49 \\
\hline \multicolumn{5}{|l|}{ Cor/raça } \\
\hline Preta & 8,49 & 7,19 & 9,01 & 8,72 \\
\hline Branca & 50,34 & 51,13 & 57,12 & 57,6 \\
\hline Parda & 41,17 & 41,67 & 33,87 & 33,68 \\
\hline \multicolumn{5}{|l|}{ Grupos etários } \\
\hline 18 a 24 anos & 5,05 & 8,45 & 11,39 & 18,87 \\
\hline 25 a 34 anos & 23,14 & 26,04 & 36,45 & 40,08 \\
\hline 35 a 44 anos & 25,56 & 25,32 & 30,43 & 25,48 \\
\hline 45 a 54 anos & 21,41 & 20,02 & 17,16 & 12,08 \\
\hline 55 a 64 anos & 14,14 & 12,25 & 3,80 & 2,80 \\
\hline 65 anos ou mais & 10,7 & 7,92 & 0,77 & 0,70 \\
\hline Total (N) & 36.201 .272 & 36.201 .272 & 64.451 & 64.451 \\
\hline
\end{tabular}

Fonte: IBGE. Censo Demográfico 2010.

Em relação à cor/raça é perceptível uma maior porcentagem de brancos entre os casais homossexuais $(57,12 \%$ e $57,6 \%$ ), o que pode estar correlacionado com a alta escolaridade desse grupo. Black, Sanders e Taylor (2007) também analisaram a composição racial dos casais homossexuais nos EUA, encontrando, na amostra utilizada por eles, 77,1\% de gays brancos e $84,4 \%$ de lésbicas brancas. No entanto, não há como comparar esses resultados com o caso brasileiro, pois a variável cor/raça para os americanos tem conotação diferente da utilizada no Brasil.

No Brasil, os responsáveis e cônjuges homossexuais são considerados jovens, com $36,45 \%$ e $40,08 \%$ na faixa de 25 a 34 anos, respectivamente. Esse fator torna evidente a diferença etária em relação aos casais heterossexuais, que estão concentrados na faixa de 35 a 44 anos. Baumle, Compton e Poston Jr. (2009) fizeram estudos sobre casais homossexuais utilizando o Censo de 2000 dos Estados Unidos. Os resultados mostraram que os casais homossexuais, distribuídos em grupos etários de menos de 30 anos, 30 a 49 anos, 50 a 69 anos e 70 anos ou mais, concentravam-se $(62,6 \%)$ na faixa de 30 a 49 anos de idade e ainda $18 \%$ entre 50 e 69 anos. Isso mostra que, comparativamente, nos Estados Unidos os casais homossexuais encontram-se numa faixa etária mais velha.

Quando analisadas as características dos responsáveis e cônjuges heterossexuais, observam-se semelhanças nas distribuições de cada variável estudada. Os responsáveis e cônjuges homossexuais também seguem distribuições semelhantes, apresentando algumas 
diferenças quanto à distribuição por grupos etários, em que os cônjuges homossexuais têm uma porcentagem relativamente maior no grupo de 18 a 24 anos $(18,87 \%)$ do que os responsáveis (11,39\%).

\section{Padrões de associação dos casais}

Nessa seção são retratados os padrões de associações entre os casais tanto homossexuais quanto heterossexuais a partir de tabelas de contingência. Após os cruzamentos das características escolhidas para a análise, foram obtidas as chamadas taxas de endogamia e exogamia entre os casais heterossexuais e homossexuais, apresentadas no Gráfico 1. Os resultados foram em sua maioria esperados, uma vez que a endogamia, como a literatura já mostrou (BECKER, 1981; RIBERIO; SILVA, 2009; LONGO, 2011; KALMIJN; FLAP, 2001), é a forma mais comum de associação. Entre os resultados obtidos, a única taxa de exogamia que ultrapassa a de endogamia está relacionada ao grupo etário para os casais homossexuais.

De acordo com os resultados no Gráfico 1, em se tratando de escolaridade, cor/raça e idade, as taxas de endogamia para os casais homossexuais são menores quando comparadas às dos heterossexuais. Em outras palavras, os casais homossexuais demonstram ser menos endogâmicos nas formas de associações, dadas essas características. Essa maior exogamia entre esses casais pode ser devida a uma primeira transgressão das normas sociais de associação, que seria a relação homoafetiva. Logo, uma segunda ruptura da norma seria mais fácil de ocorrer (ROSENFELD; KIM, 2005; SCHWARTZ; GRAF, 2009). Entretanto, mesmo sendo menos endogâmicos, esses casais ainda seguem o padrão de endogamia que existe entre os casais heterossexuais em relação à escolaridade e cor/raça.

As taxas de endogamia e exogamia permitem uma visão sintética sobre os padrões de seletividade. Dessa forma, analisar as tabelas de contingência por característica contribui para um olhar mais específico em relação às variáveis escolaridade, cor/raça e grupo etário. Nas tabelas de contingência é possível perceber em quais categorias estão concentradas as uniões mais endogâmicas ou exogâmicas.

Analisando as tabelas de contingência por nível de instrução (Tabela 2), verifica-se uma concentração de associações nos níveis extremos de escolaridade, ou seja, nas faixas de 0 a 7 anos de estudo e 15 anos ou mais há maiores porcentagens de casais ditos endogâmicos tanto para os heterossexuais $(64,76 \%$ e $68,61 \%)$ como para os homossexuais $(60,11 \%$ e $68,06 \%)$. 
GRÁFICO 1

Taxas de endogamia e exogamia dos casais heterossexuais e homossexuais, segundo grupo etário, cor/raça e escolaridade Brasil - 2010

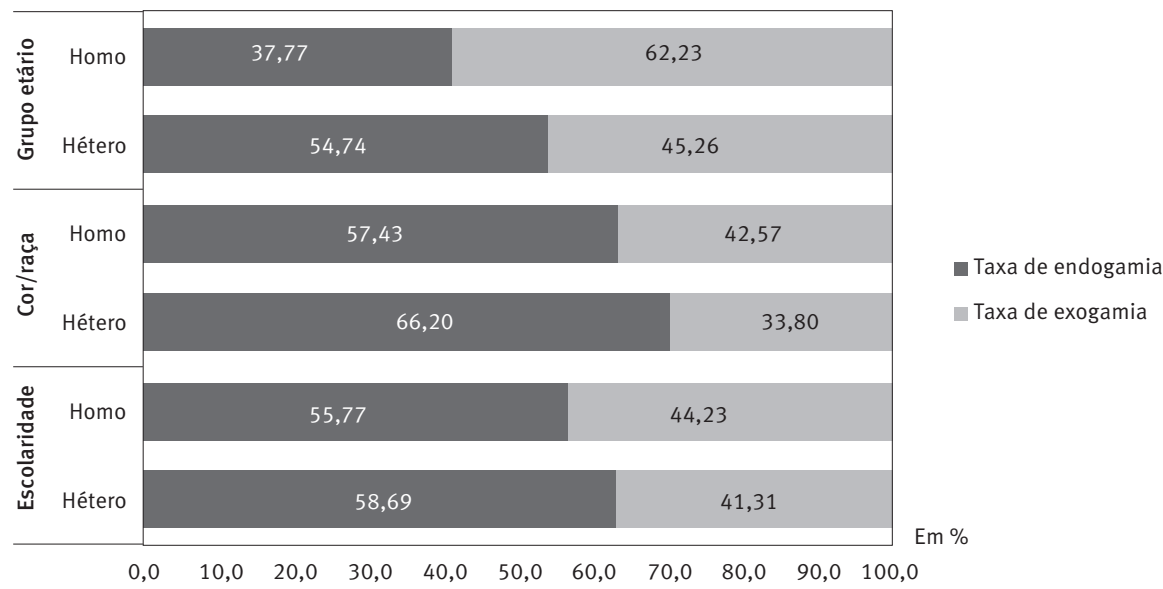

Fonte: IBGE. Censo Demográfico 2010.

TABELA 2

Tabelas de contingência padronizadas dos casais heterossexuais e homossexuais, por nível de instrução Brasil - 2010

\begin{tabular}{|c|c|c|c|c|c|}
\hline & & & & & Em porcenta \\
\hline \multirow{3}{*}{$\begin{array}{c}\text { Responsável } \\
\text { heterossexual }\end{array}$} & \multicolumn{5}{|c|}{ Cônjuge heterossexual } \\
\hline & \multicolumn{5}{|c|}{ Nível de instrução } \\
\hline & $\begin{array}{l}0 \text { a } 7 \\
\text { anos }\end{array}$ & $\begin{array}{l}8 \text { a } 10 \\
\text { anos }\end{array}$ & $\begin{array}{c}11 \text { a } 14 \\
\text { anos }\end{array}$ & $\begin{array}{c}15 \text { anos ou } \\
\text { mais }\end{array}$ & Total \\
\hline \multicolumn{6}{|l|}{ Nível de instrução } \\
\hline 0 a 7 anos & 64,76 & 20,97 & 10,99 & 3,28 & 100,00 \\
\hline 8 a 10 anos & 21,21 & 50,32 & 20,59 & 7,88 & 100,00 \\
\hline 11 a 14 anos & 11,08 & 21,27 & 47,42 & 20,23 & 100,00 \\
\hline 15 anos ou mais & 2,95 & 7,44 & 21,00 & 68,61 & 100,00 \\
\hline Total & 100,00 & 100,00 & 100,00 & 100,00 & \\
\hline N. abs. & 17.364 .142 & 5.950 .822 & 9.227 .327 & 3.658 .981 & 36.201 .272 \\
\hline \multirow{3}{*}{$\begin{array}{l}\text { Responsável } \\
\text { homossexual }\end{array}$} & \multicolumn{5}{|c|}{ Cônjuge homossexual } \\
\hline & \multicolumn{5}{|c|}{ Nível de instrução } \\
\hline & $\begin{array}{l}0 \text { a } 7 \\
\text { anos }\end{array}$ & $\begin{array}{l}8 \text { a } 10 \\
\text { anos }\end{array}$ & $\begin{array}{c}11 \text { a } 14 \\
\text { anos }\end{array}$ & $\begin{array}{c}15 \text { anos ou } \\
\text { mais }\end{array}$ & Total \\
\hline \multicolumn{6}{|l|}{ Nível de instrução } \\
\hline 0 a 7 anos & 60,11 & 25,52 & 11,19 & 3,18 & 100,00 \\
\hline 8 a 10 anos & 24,76 & 49,64 & 18,45 & 7,16 & 100,00 \\
\hline 11 a 14 anos & 12,81 & 18,43 & 47,16 & 21,60 & 100,00 \\
\hline 15 anos ou mais & 2,32 & 6,42 & 23,20 & 68,06 & 100,00 \\
\hline Total & 100,00 & 100,00 & 100,00 & 100,00 & \\
\hline N. abs. & 12.480 & 10.054 & 26.135 & 15.782 & 64.451 \\
\hline
\end{tabular}

Fonte: IBGE. Censo Demográfico 2010. 
Além da concentração de uniões nos extremos das categorias educacionais, a Tabela 2 mostra que na faixa de 11 a 14 anos de estudo há uma distribuição de uniões exogâmicas com porcentagens menos díspares do que nas outras faixas educacionais. Essa forma de distribuição de uniões ocorre tanto entre heterossexuais como entre os homossexuais.

Ademais, no grupo de 11 a 14 anos de estudo, observam-se as menores porcentagens de uniões endogâmicas por nível de instrução (47,42\% e 47,16\%) para os dois tipos de casais. Esse resultado aponta para uma maior transposição de barreiras sociais na faixa de 11 a 14 anos de estudo em relação às outras categorias educacionais.

A análise das uniões por cor/raça entre os casais heterossexuais e homossexuais, mostrada na Tabela 3, é bastante similar ao se comparar a diagonal central de cada tabela de contingência. Assim, verifica-se uma maior endogamia entre pretos heterossexuais $(72,79 \%)$ e homossexuais $(64,32 \%)$.

TABELA 3

Tabelas de contingência padronizadas dos casais heterossexuais e homossexuais, por cor/raça Brasil - 2010

Em porcentagem

\begin{tabular}{|c|c|c|c|c|}
\hline \multirow{3}{*}{$\begin{array}{l}\text { Responsável } \\
\text { heterossexual }\end{array}$} & \multicolumn{4}{|c|}{ Cônjuge heterossexual } \\
\hline & \multicolumn{4}{|c|}{ Cor/raça } \\
\hline & Preto & Branco & Pardo & Total \\
\hline \multicolumn{5}{|l|}{ Cor/raça } \\
\hline Preto & 72,79 & 11,97 & 15,24 & 100,00 \\
\hline Branco & 12,70 & 66,72 & 20,57 & 100,00 \\
\hline Pardo & 14,51 & 21,30 & 64,19 & 100,00 \\
\hline Total & 100,00 & 100,00 & 100,00 & \\
\hline N. abs. & 2.604 .291 & 18.510 .886 & 15.086 .095 & 36.201 .272 \\
\hline \multirow{3}{*}{$\begin{array}{l}\text { Responsável } \\
\text { homossexual }\end{array}$} & \multicolumn{4}{|c|}{ Cônjuge homossexual } \\
\hline & \multicolumn{4}{|c|}{ Cor/raça } \\
\hline & Preto & Branco & Pardo & Total \\
\hline \multicolumn{5}{|l|}{ Cor/raça } \\
\hline Preto & 64,32 & 16,31 & 19,36 & 100,00 \\
\hline Branco & 18,89 & 56,92 & 24,18 & 100,00 \\
\hline Pardo & 16,79 & 26,76 & 56,45 & 100,00 \\
\hline Total & 100,00 & 100,00 & 100,00 & \\
\hline N. abs. & 5.622 & 37.125 & 21.704 & 64.451 \\
\hline
\end{tabular}

Fonte: IBGE. Censo Demográfico 2010.

É interessante verificar que os valores de exogamia de cor/raça entre os homossexuais demonstram que as barreiras de associação entre esses casais parecem ser menos intensas do que para os casais heterossexuais. Isso fica evidente quando se nota a porcentagem maior de uniões entre brancos e pretos do que entre pretos para casais homossexuais. Ao se fazer o comparativo para heterossexuais, as porcentagens de uniões entre brancos e pretos são inferiores àquelas observadas para homossexuais. Logo, esses resultados diferem um pouco dos padrões de seletividade marital entre casais heterossexuais, o que deixa margem para um aprofundamento no entendimento das forças sociais que atuam entre os casais homoafetivos. 
O quesito idade como característica de escolha dos parceiros já foi estudado por outros autores, como Bergstrom e Bagnoli (1993) em relação a casais heterossexuais, e Hayes (1995), que fez um estudo sobre as preferências de idade entre parceiros homossexuais. Bergstrom e Bagnoli (1993) colocam uma idade média de casamento para homens maior do que para mulheres nas relações heterossexuais. Isso porque, segundo os autores, as mulheres são valorizadas por suas habilidades para cuidar da casa e dos filhos, enquanto os homens são valorizados pela capacidade de "prover a família". A literatura que trabalha com seletividade entre casais homossexuais em relação à idade mostra que homens têm preferência por parceiros mais novos, enquanto as mulheres não demonstram essa preferência (HAYES, 1995). De acordo com os resultados da Tabela 4, percebe-se uma alta endogamia nos grupos etários das extremidades. No entanto, o Gráfico 1 apontou para uma maior taxa de exogamia entre os casais homossexuais, sendo que, na Tabela 4, essas taxas estão concentradas nos níveis etários próximos da diagonal central. Logo, existe uma diferença etária entre os casais, mas é preciso investigar posteriormente quão grande é esse hiato.

TABELA 4

Tabelas de contingência padronizadas dos casais heterossexuais e homossexuais, por grupos etários Brasil - 2010

\begin{tabular}{|c|c|c|c|c|c|c|c|}
\hline & & & & & & & Em porcenta \\
\hline \multirow{3}{*}{$\begin{array}{l}\text { Responsável } \\
\text { heterossexual }\end{array}$} & \multicolumn{7}{|c|}{ Cônjuge heterossexual } \\
\hline & \multicolumn{7}{|c|}{ Grupos etários } \\
\hline & $\begin{array}{c}18 \text { a } 24 \\
\text { anos }\end{array}$ & $\begin{array}{c}25 \text { a } 34 \\
\text { anos }\end{array}$ & $\begin{array}{c}35 \text { a } 44 \\
\text { anos }\end{array}$ & $\begin{array}{c}45 \text { a } 54 \\
\text { anos }\end{array}$ & $\begin{array}{c}55 \text { a } 64 \\
\text { anos }\end{array}$ & $\begin{array}{c}65 \text { anos ou } \\
\text { mais }\end{array}$ & Total \\
\hline \multicolumn{8}{|l|}{ Grupos etários } \\
\hline 18 a 24 anos & 68,24 & 24,91 & 4,68 & 1,33 & 0,46 & 0,32 & 100,00 \\
\hline 25 a 34 anos & 27,30 & 49,74 & 17,57 & 3,65 & 1,13 & 0,57 & 100,00 \\
\hline 35 a 44 anos & 3,63 & 21,55 & 51,10 & 17,93 & 4,16 & 1,62 & 100,00 \\
\hline 45 a 54 anos & 0,65 & 3,09 & 22,81 & 51,00 & 17,89 & 4,57 & 100,00 \\
\hline 55 a 64 anos & 0,14 & 0,58 & 3,18 & 23,10 & 55,05 & 17,99 & 100,00 \\
\hline 65 anos ou mais & 0,04 & 0,13 & 0,66 & 2,99 & 21,31 & 74,92 & 100,00 \\
\hline Total & 100,00 & 100,00 & 100,00 & 100,00 & 100,00 & 100,00 & \\
\hline N. abs. & 3.059 .262 & 9.428 .112 & 9.165 .221 & 7.246 .406 & 4.433 .600 & 2.868 .671 & 36.201 .272 \\
\hline \multirow{3}{*}{$\begin{array}{l}\text { Responsável } \\
\text { homossexual }\end{array}$} & \multicolumn{7}{|c|}{ Cônjuge homossexual } \\
\hline & \multicolumn{7}{|c|}{ Grupos etários } \\
\hline & $\begin{array}{c}18 \text { a } 24 \\
\text { anos }\end{array}$ & $\begin{array}{c}25 \text { a } 34 \\
\text { anos }\end{array}$ & $\begin{array}{c}35 \text { a } 44 \\
\text { anos }\end{array}$ & $\begin{array}{c}45 \text { a } 54 \\
\text { anos }\end{array}$ & $\begin{array}{c}55 \text { a } 64 \\
\text { anos }\end{array}$ & $\begin{array}{c}65 \text { anos ou } \\
\text { mais }\end{array}$ & Total \\
\hline \multicolumn{8}{|l|}{ Grupos etários } \\
\hline 18 a 24 anos & 58,10 & 25,84 & 10,42 & 5,04 & 0,41 & 0,19 & 100,00 \\
\hline 25 a 34 anos & 28,17 & 38,37 & 19,42 & 10,22 & 3,41 & 0,42 & 100,00 \\
\hline 35 a 44 anos & 8,65 & 22,61 & 29,43 & 22,18 & 10,97 & 6,17 & 100,00 \\
\hline 45 a 54 anos & 3,36 & 10,05 & 26,13 & 36,05 & 20,13 & 4,28 & 100,00 \\
\hline 55 a 64 anos & 1,29 & 2,93 & 9,73 & 21,71 & 40,17 & 24,17 & 100,00 \\
\hline 65 anos ou mais & 0,48 & 0,23 & 4,88 & 4,80 & 24,89 & 64,73 & 100,00 \\
\hline Total & 100,00 & 100,00 & 100,00 & 100,00 & 100,00 & 100,00 & \\
\hline N. abs. & 12.164 & 25.831 & 16.420 & 7.786 & 1.802 & 448 & 64.451 \\
\hline
\end{tabular}

Fonte: IBGE. Censo Demográfico 2010. 


\section{Modelos log-lineares}

Nessa parte são analisados os modelos de melhor ajuste, ou seja, aqueles que, segundo as estatísticas, demonstram quais características têm maior importância em relação aos padrões de seletividade dos casais analisados. Inicialmente é feita a estimação do modelo de independência que é quando não se controla a probabilidade de ocorrência das associações por nenhuma variável.

Em seguida, adicionam-se variáveis de controle em cada modelo, como cor/raça, escolaridade e idade. Depois são estimados modelos com interações entre as variáveis de forma a perceber se uma variável em relação à outra explica mais os padrões do que elas separadamente (Tabela 5). Para analisar os modelos e escolher aquele que se ajusta melhor aos dados é preciso considerar o menor valor de BIC, o maior valor de $R^{2}$ e os graus de liberdade do modelo (AGRESTI, 1990). O $R^{2}$ é uma estatística utilizada por Andrade (1997) que é feita a partir dos valores de $G^{2}$ dos modelos e pode ser calculado da seguinte maneira: $R^{2}=\left(1-\frac{G_{C}^{2}}{G_{N}^{2}}\right)$

Dessa maneira, para casais homossexuais, o modelo que melhor explica o padrão de associação entre os parceiros é o de interação entre cor, escolaridade e idade, que possui o menor BIC (-5457.48) e um $R^{2}$ de 53,87\%. A interpretação desse resultado é mostrar que as três variáveis têm papel importante no processo de seletividade dos casais. No entanto, o modelo controlado por essas variáveis sem o fator de interação também se ajusta muito bem aos dados com um BIC (-4673.73) e um $R^{2}$ de 39,03\%, mas tem mais graus de liberdade do que o modelo de interação. Logo, é preciso levar em conta que, no modelo de interação, perdem-se 56 graus de liberdade e, no sem interação, perdem-se apenas 20. Esse fator deve ser considerado, já que o BIC é bastante sensível aos graus de liberdade em grandes amostras.

Entre os casais heterossexuais, o melhor modelo de ajuste é o que tem cor/raça, escolaridade e grupo etário como variáveis de controle com interações, pois esse modelo possui o menor BIC (3942150) e um $R^{2}$ de $75,98 \%$. Esses resultados mostram que, tanto para parceiros heterossexuais como para os homossexuais, as variáveis cor/raça, escolaridade e idade influenciam os padrões de associações entre os casais. É claro que os outros modelos dão pistas de qual variável tem uma influência provavelmente maior nas escolhas conjugais para cada tipo de casal. Esse é o caso do modelo sem interação entre cor/raça, escolaridade e grupo etário para casais heterossexuais. Esse modelo, se comparado com os outros, tem um BIC baixo (8742575) e um $R^{2}$ de 47,01\%, que é um valor maior que o dos outros modelos. No entanto, não há como afirmar qual variável tem impacto maior nos padrões, podendo-se apenas supor a partir dos modelos. 
TABELA 5

Resumo das estatísticas de ajustes dos modelos log-lineares

\begin{tabular}{|c|c|c|c|c|c|c|}
\hline Modelos & $\mathrm{G}^{2}$ & $\Delta \mathrm{G}^{2}$ & gl & $\Delta \mathrm{gl}$ & $\mathrm{BIC}$ & $\mathrm{R}^{2}(\%)$ \\
\hline \multicolumn{7}{|l|}{ Casal homossexual } \\
\hline Independência & 7014.80 & & 1272 & & -2078.90 & 0 \\
\hline Cor/raça & 5946.10 & 1068.69 & 1268 & 4 & -3118.99 & 15,23 \\
\hline Escolaridade & 6540.24 & 474.55 & 1266 & 6 & -2510.56 & 6,77 \\
\hline Cor e escolaridade & 5482.34 & 1532.45 & 1262 & 10 & -3539.86 & 21,85 \\
\hline Cor e idade & 4834.64 & 2180.16 & 1258 & 14 & -4158.97 & 31,08 \\
\hline Cor, escolaridade e idade & 4276.98 & 2737.81 & 1252 & 20 & -4673.73 & 39,03 \\
\hline \multicolumn{7}{|l|}{ Modelo de interação } \\
\hline Cor/raça & 5607.66 & 1407.14 & 1264 & 8 & -3428.84 & 20,06 \\
\hline Escolaridade & 5848.34 & 1166.46 & 1257 & 15 & -3138.12 & 16,63 \\
\hline Cor e escolaridade & 5207.14 & 1807.65 & 1250 & 22 & -3729.27 & 25,77 \\
\hline Cor e idade & 4681.57 & 2333.22 & 1238 & 34 & -4169.05 & 33,26 \\
\hline Cor, escolaridade e idade & 3235.87 & 3778.93 & 1216 & 56 & -5457.48 & 53,87 \\
\hline \multicolumn{7}{|l|}{ Casal heterossexual } \\
\hline Independência & 16572198.46 & & 4677 & & $1.65 E+07$ & 0 \\
\hline Cor/raça & 13805672.36 & 2766526.10 & 4673 & 4 & $1.38 \mathrm{E}+07$ & 16,69 \\
\hline Escolaridade & 13118156.75 & 3454041.71 & 4671 & 6 & $1.31 \mathrm{E}+07$ & 20,84 \\
\hline Cor e escolaridade & 10187954.48 & 6384243.98 & 4667 & 10 & $1.01 \mathrm{E}+07$ & 38,52 \\
\hline Cor e idade & 12534636.12 & 4037562.34 & 4663 & 14 & $1.25 E+07$ & 24,36 \\
\hline Cor, escolaridade e idade & 8781930.01 & 7790268.45 & 4657 & 20 & 8742575 & 47,01 \\
\hline \multicolumn{7}{|l|}{ Modelo de interação } \\
\hline Cor/raça & 12527496.91 & 4044701.55 & 4669 & 8 & $1.25 \mathrm{E}+07$ & 24,41 \\
\hline Escolaridade & 11311176.22 & 5261022.24 & 4662 & 15 & $1.13 E+07$ & 31,75 \\
\hline Cor e escolaridade & 9934077.16 & 6638121.30 & 4655 & 22 & 9894739 & 40,06 \\
\hline Cor e idade & 12483572.37 & 4088626.09 & 4643 & 34 & $1.24 \mathrm{E}+07$ & 24,67 \\
\hline Cor, escolaridade e idade & 3981191.63 & 12591006.83 & 4620 & 57 & 3942150 & 75,98 \\
\hline
\end{tabular}

Fonte: IBGE. Censo Demográfico 2010.

Os resultados dos modelos demonstram que as características educacionais entre os casais homossexuais não constituem sozinhas uma barreira para as associações desses casais. As características de cor/raça e idade parecem ter uma importância maior nas decisões dos parceiros. É claro que a educação não deixou de ser um fator de seletividade, mas simplesmente para esse grupo as associações dependem das outras características também. Entre os casais heterossexuais isso não acontece, já que a escolaridade, juntamente com a cor/raça como variáveis de interação, é o segundo melhor modelo de ajuste. Nesse sentido, os casais heterossexuais dão uma importância muito grande ao nível de instrução do parceiro, assim como a cor/raça.

\section{Considerações finais}

Esse artigo teve por objetivo testar a hipótese da seletividade marital entre casais homossexuais e heterossexuais no Brasil. 0 estudo das similaridades e diferenças entre 
esses grupos é relevante, pois se trata da tentativa de compreender como esses arranjos familiares se comportam em relação à formação de um casal.

Por meio das tabelas de contingência em relação ao nível de instrução, fica claro o comportamento semelhante entre os dois tipos de casais na formação de uniões endogâmicas. É importante apontar que, mesmo com um corte etário de 18 a 65 anos ou mais, os resultados obtidos em relação à escolaridade são próximos aos encontrados em outros trabalhos (RIBEIRO; SILVA, 2009; LONGO, 2011) que restringiram o grupo etário a fim de controlar a questão da mutabilidade da variável de escolaridade ao longo do tempo.

Em relação à cor/raça prevalece a endogamia entre os dois tipos de casais, mas novamente as barreiras de união entre eles são diferentes. Para os heterossexuais, as barreiras educacionais são bastante rígidas em uniões entre brancos com pretos, enquanto entre pardos e brancos essa barreira é menos intensa, mostrando que tal resultado está de acordo com os estudos de Ribeiro e Silva (2009). Entre os casais homossexuais, as barreiras de associação são mais flexíveis em se tratando de uniões entre brancos e pretos quando comparados aos padrões dos casais heterossexuais.

A taxa de exogamia só é maior entre casais homossexuais referentes ao grupo etário, o que demonstra, juntamente com os resultados dos modelos log-lineares, que a idade para os casais homossexuais é uma característica importante para a escolha do parceiro. Já entre os casais heterossexuais a idade é uma característica complementar, dado o valor da taxa de endogamia nesse grupo, com menor peso de acordo com os modelos com melhor ajuste.

Dessa maneira, a partir dos resultados obtidos nesse trabalho, percebe-se que existem dois grupos em questão que estão inseridos e influenciados pelas mesmas forças sociais, mas que, devido a algumas diferenças nas escolhas conjugais, fazem com que se tenham distinções na formação do casal. Esse tipo de inferência está de acordo com a literatura sobre seletividade marital para casais heterossexuais (BECKER, 1981; RIBEIRO; SILVA, 2009; LONGO, 2011). No entanto, deve ser lembrado novamente que, como não havia estudos no Brasil sobre os comportamentos dos casais homossexuais em relação aos padrões de seletividade, não há como se ter certeza ainda dos desdobramentos dessas escolhas ao longo do tempo. Diante disso, é preciso investir em mais estudos e pesquisas que captem essas relações para que se amplie o conhecimento na área de seletividade marital, fundamental para a compreensão mais ampla da constituição dos arranjos familiares.

\section{Referências}

AGRESTI, A. Categorical data analysis. New York: John Wiley \& Sons, 1990.

ANDRADE, F. C. D. Níveis e padrões de mobilidade social em cinco regiões metropolitanas. 1997. 165 f. Dissertação (Mestrado em Demografia) - Centro de Desenvolvimento e Planejamento Regional, Universidade Federal de Minas Gerais, Belo Horizonte, 1997.

BADGETT, M. V. L. Money, myths, and change: the economic lives of lesbians and gay men. Chicago: University of Chicago Press, 2001. 
BAUMLE, K. A.; COMPTON, D.; POSTON JR., L. D. Same-sex partners: the social demography of sexual orientation. Albany: State University of New York Press, 2009.

BECKER, G. S. Assortative mating in marriage market. In: BECKER, G. S. A treatise on the family. 2. ed. Cambridge: Harvard University Press, 1981. cap. 4, p.108-134

BERGSTROM, T. C.; BAGNOLI, M. Courtship as a waiting game. Journal of Political Economy, Chicago, v. 101, n. 1, p. 185-202, 1993.

BLACK, D.; SANDERS, G.S.; TAYLOR, J.L. The economics of lesbian and gay families. Jounal of Economic Perspectives, v. 21, n. 2, p. 53-70, 2007.

BLAU, P. M.; SCHWARTZ, J. Crosscutting social circles. London: Academic Press,1984.

BLOSSFELD, H. P.; TIMM, A. (Eds.). Who marries whom? Educational systems as marriage markets in modern societies. Dordrecht: Kluwer Academic Publishers, 2003.

GOODMAN, L. A. Analyzing qualitative/categorical data: log-linear models and latent structure analysis. Cambridge: Abt Books, 1978.

HAYES, A. F. Age preferences for same and opposite-sex partners. Journal of Social Psychology, n. 135, p. 125-33, 1995.

IBGE. Censo Demográfico de 2010 - Notas Metodológicas. Rio de Janeiro, 2010. Disponível em 〈http://www.ibge.gov.br/home/estatistica/populacao/cens02010/resultados_gerais_amostra/ resultados_gerais_amostra_tab_uf_microdados.shtm>. Acesso em: 08 mar. 2012.

JEPSEN, L. K.; JEPSEN, C. A. An empirical analysis of the matching patterns of same-sex and opposite-sex couples. Demography, v. 39, n. 3, p. 435-54, 2002.

KALMIJN, M.; FLAP, H. Assortative meeting and mating: unintended consequences of organized settings for partner choices. Social Forces, v. 79, n. 4, p. 1289-1312, June 2001.

LIMA, M. O quadro atual das desigualdades. In: HASENBALG, C.; SILVA, N. V.; LIMA, M. Cor e estratificação social. Rio e Janeiro: Contra Capa, 1999. p. 231-240.

LONGO, L. A. F. B. Uniões intra e inter-raciais, status marital, escolaridade e religião no Brasil: um estudo sobre a seletividade marital feminina, 1980-2000. 2011. Tese (Doutorado em Demografia) Departamento de Demografia, Universidade de Minas Gerais, Belo Horizonte, 2011.

MELLO, L. Outras famílias: a construção social da conjugalidade homossexual no Brasil. Cadernos Pagu, v. 24, p. 197-225, 2005.

RIBEIRO, C. A. C.; SILVA, N. V. Cor, educação e casamento: tendência da seletividade marital no Brasil, 1960 a 2000. Dados: Revista de Ciências Sociais, v. 52, n. 1, p.7-51, 2009.

ROSENFELD, M. J.; KIM, B. The independence of young adults and the rise of interracial and same-sex unions. American Sociological Review, n. 70, p. 541-562, 2005.

SCHWARTZ, C. R.; GRAF, N. L. Assortative matching among same-sex and different-sex couples in the United States, 1990-2000. Demographic Research, n. 21, p. 843-878, 2009.

SILVA, N. Duas décadas de seletividade marital educacional no Brasil. In: HASENBALG, C.; SILVA, N. (Eds.). Origens e destinos. Rio de Janeiro: Topbooks, 2003. 


\title{
Sobre as autoras
}

Fernanda Fortes de Lena é mestranda em Demografia na Universidade Estadual de Campinas e formada em Ciências Econômicas pela Universidade Federal de Minas Gerais - UFMG.

Ana Maria Hermeto Camilo de Oliveira é doutora em Demografia pela Universidade Federal de Minas Gerais - UFMG. Professora associada pela UFMG.

\section{Endereço para correspondência}

\author{
Fernanda Fortes de Lena \\ Rua Cora Coralina, 100, Prédio IFCH \\ 13083-896 - Campinas-SP, Brasil \\ Ana Maria Hermeto Camilo de Oliveira \\ Av. Antônio Carlos, 6627, Prédio Face, 3ํandar, Pampulha \\ 31270-901 - Belo Horizonte-MG, Brasil
}

\begin{abstract}
Assortative mating patterns of homosexual and heterosexual couples in Brazil

This paper aims to analyze assortative mating patterns between heterosexual and homosexual couples in Brazil, taking into account parameters such as education, color/race and age group. A descriptive analysis of the data was initially carried out in order to characterize the population studied and the differences between these types of couples. This paper also uses contingency tables and log-linear models to understand the forms of associations between couples and which variables influence mating patterns. The results show that color/race and education have greater influence on the selectivity of heterosexual couples, while color/race and age group are more relevant for homosexual couples when choosing their partners. Thus, it is possible to identify differences in the selective characteristics of these couples as well as different patterns. These findings pave the way for subsequent studies that can deepen the understanding of the distinctions between these patterns, in order to find ways of trying to explain them and their possible consequences in Brazil.
\end{abstract}

Keywords: Assortative mating. Homosexuals. Marriage. Education. Family arrangements.

\section{Resumen}

Patrones de selectividad de las parejas homosexuales y heterosexuales en Brasil

El objetivo de este artículo es analizar los patrones de selectividad marital entre las parejas heterosexuales y homosexuales en Brasil, investigando para ello los niveles de escolaridad, color/raza y grupo etario. Inicialmente se realizó un análisis descriptivo de los datos con el fin de caracterizar a la población estudiada y los diferenciales entre los tipos de parejas. Además, el estudio utiliza tablas de contingencia y modelos log-lineares para entender las formas de asociación entre las parejas y las variables que influyen en la selectividad de sus miembros. En relación con los patrones de selectividad, los resultados muestran que el color/raza y la 
escolaridad tienen mayor influencia en las parejas heterosexuales, mientras que el color/raza y el grupo etario al que se pertenece son más relevantes para las parejas homosexuales. Por lo tanto, se pueden identificar diferencias entre las características de la selectividad de estas parejas y sus patrones, lo que abre un espacio para estudios posteriores que puedan profundizar la comprensión de las diferencias entre estos patrones, con el fin de intentar explicar estas distinciones y sus posibles consecuencias en el país.

Palabras clave: Selectividad marital. Homosexuales. Matrimonio. Educación. Arreglos familiares.

Recebido para publicação em 17/12/2013

Aceito para publicação em 29/03/2015 
